\title{
Research on Confirming the Weighted Value in Software Quality Model Based on Analytic Hierarchy Process
}

\author{
Ruibing Shi, Hongyuan Tian, Wei Du, Hongquan Wu, Anyu Xie, Qingwei Li \\ Baicheng Weapon Test Center, Baicheng137001, China
}

shiruibing198121@sina.com

\begin{abstract}
Keywords: Weighted Value of Software Quality Model; Analytic Hierarchy Process; Extreme Judgment Rejecting
\end{abstract}

\begin{abstract}
Some problems are existed in confirming the weighted value in the software quality model, for example, the method is relatively rough and how the abnormal value is rejected while judging the weighted value. Aiming at these problems, it is pointed out that the scientific hierarchy structure of quality characteristics and sub characteristics should be built based on the analytic hierarchy process. Through the construction of judgment matrix, single hierarchical arrangement, total hierarchical arrangement and consistency check, the comprehensive weighted value of sub characteristics of bottom quality will be confirmed. Then by the extreme judgment rejecting method, the abnormal judgment value will be rejected to avoid the unreasonable comprehensive weighted value. Finally, by adopting this method in the test of one certain communication system software, the scientificity and rationality is verified.
\end{abstract}

\section{Introduction}

Software test evaluation is the software quality evaluation which is done for the purpose of testing and evaluating the software in the weapon system. Its process is to confirm the rate of software test evaluation, the range, the pattern, the method and the input document, quality model weighted value, etc. Among them, the confirmation of quality model weighted value is the major foundation to make the final quantitative evaluation of the tested software system. So the related research on it has increased a lot these years. But there are some common problems. First, the method of confirming the weighted value is relatively rough and it is even confirmed according to the experience. Second, there is little research on how to reject the abnormal value during the judgment of weighted value. Aiming at these problems, a method is need to be found to solve them and to have a more scientific, objective and real quantitative evaluation of tested software system.

\section{Confirmation of Weighted Value}

Weighted value is the comparison of the relative importance between any two elements among many elements under a certain rule. There are many methods to confirm the weighted value and the analytic hierarchy process is a method which is relatively mature and widely used. It mainly includes [1-3]: first, build the hierarchical structure model; second, build the judgment matrix through 1-9 scale and paired comparison; third, single hierarchical arrangement is done; fourth, the largest eigenvalue of judgment matrix and weight vector of normalization is got through root method; fifth, consistency check is done to confirm whether the consistency of judgment matrix can satisfy the requirements; sixth, the total hierarchical arrangement is done.

\section{Extreme Judgment Rejection}

When the weighted value is confirmed by using the analytic hierarchy process, the comprehensive assessment of each element's weight needs to be done by many experts. In the actual work, because of different expert's preferences and one-sidedness of judging the objects, the extreme judgment will be given when comparing the relative importance of comparative indices, which is the judgment abnormal value. The existence of extreme judgment abnormal value will 
influence the quality of comprehensive judgment, so the effective check and rejection should be done.

Set the calculation model of calculating the weight evaluation average value of each element:

$$
\bar{\eta}_{i}=\frac{1}{k} \sum_{j=1}^{k} \omega_{i j}
$$

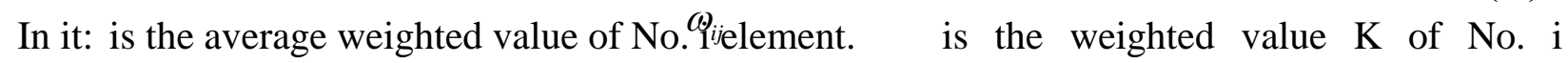
element which $\bar{\eta}_{i}$ is given by No. $\mathrm{j}$ expert. $\mathrm{K}$ is the number of experts .

The set variance calculation model:

$$
S^{2}=\frac{1}{k-1} \sum_{j=1}^{k}\left(\omega_{i j}-\bar{\eta}_{i}\right)^{2}
$$

$3 \sigma$ rule can be used as the criterion of rejecting the extreme judgment. The difference between each judgment and the sample is:

$$
\delta_{i k}=\omega_{i k}-\bar{\eta}_{i}
$$

If $\left|\delta_{i k}\right|<3 S$, the weighted value of No. i element gotten by No. k expert is up to the standard. If not, the value will be rejected and the judgment will be made again.

\section{Case Analysis}

\subsection{Building the Hierarchical Structure}

The software test evaluation of one certain communication system is used as an example to elaborate the computation process of above models in details. According to the relationship between software quality characteristics and sub characteristics, the following hierarchical structure model is built, which is shown in Figure 1:

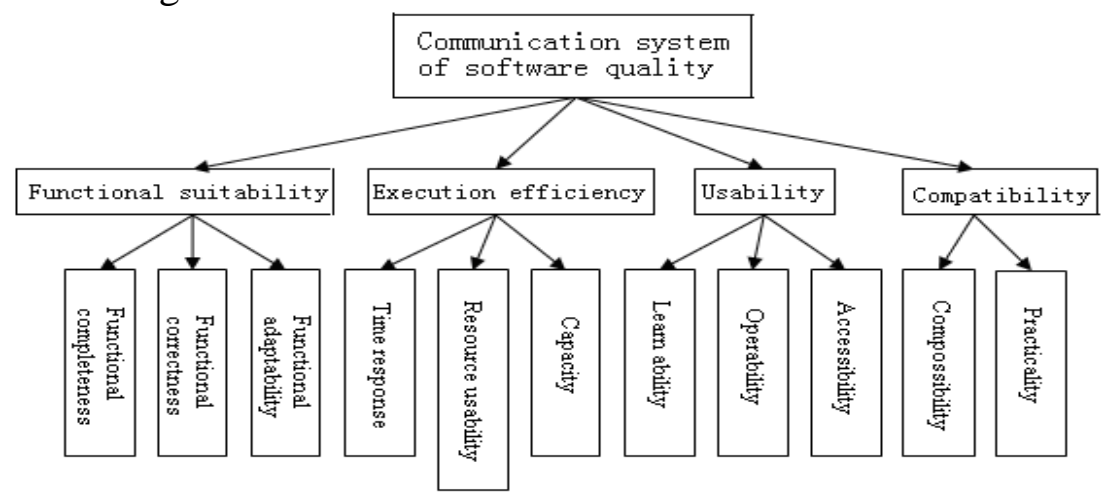

Figure 1 Figure of hierarchical structure model

\subsection{Building the Judgment Matrix}

The judgment matrix is built according to the comparison of relative importance of elements in each hierarchy in the communication system. In order to make the relative importance among elements quantitative, the 1-9 scale method put forward by T.L.Saaty et al according to the psychology is adopted, which is shown in the following chart. Chart $1 \quad 1 \sim 9$ Scale Value

\begin{tabular}{|c|c|c|}
\hline Relative Importance & Definition & $a_{i j}$ explanation \\
\hline 1 & Equally Important & Target i is as important as Target.j. \\
\hline 3 & Slightly Important & $\begin{array}{c}\text { Target } \mathrm{i} \text { is slightly more important than } \\
\text { Target j. }\end{array}$ \\
\hline 5 & Important & Target $\mathrm{i}$ is more important than Target j. \\
\hline 7 & Obviously Important & $\begin{array}{c}\text { Target } \mathrm{i} \text { is obviously more important } \\
\text { than Target j. }\end{array}$ \\
\hline 9 & Absolutely Important & Target i is absolutely more important \\
\hline
\end{tabular}




\begin{tabular}{|c|c|c|}
\hline & & than Target $\mathrm{j}$. \\
\hline 2468 & $\begin{array}{c}\text { Between the Adjacent } \\
\text { Importance }\end{array}$ & $a_{i j}=1 / a_{j i}$ \\
\hline $\begin{array}{c}\text { Reciprocal of Each } \\
\text { Number }\end{array}$ & $\begin{array}{c}\text { Two targets are compared } \\
\text { in return }\end{array}$ & \\
\hline
\end{tabular}

One expert built the following judgment matrix of each hierarchy according to the 1-9 scale method.

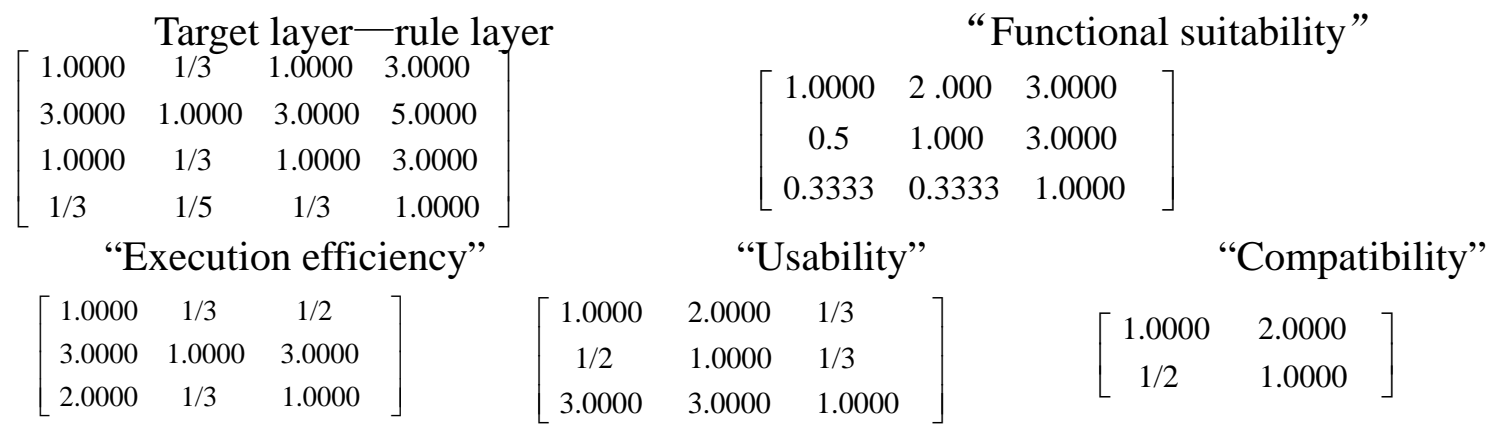

\subsection{Single Hierarchical Arrangement}

\subsubsection{Computational process of single hierarchical arrangement}

The weight vector of each judgment matrix is calculated according to the root method. The specific computational process is as follows [4-5]:

(1) The elements of each line in the matrix are multiplied and rooted by m;

$$
b_{j}=\sqrt[m]{\prod_{i j}^{m} a_{i j}}
$$

(2) Normalizationn treatment is done to the column vectors and weighted vector quantity is got.

$$
\bar{b}_{j}=\frac{b_{j}}{\sum_{j=1}^{m} b_{j}}
$$

(3) The consistency index value corresponding to judgment matrix is got:

(4) Consistency check: $\frac{\left(\lambda_{\max }-n\right)}{C_{n-1}}$

Compare the CI value in the formula (6) and the average random consistency index RI in the following chart 1-9 scale. The consistency scale value CR is got

$$
\frac{C I}{R I} \quad C R=
$$

Chart $2 \quad 1 \sim 9$ Scale $R I$ value

\begin{tabular}{|c|c|c|c|c|c|c|c|c|c|}
\hline $\begin{array}{c}\text { Scale of judgment } \\
\text { matrix } h\end{array}$ & 1 & 2 & 3 & 4 & 5 & 6 & 7 & 8 & 9 \\
\hline$R I$ value & 0 & 0 & 0.58 & 0.89 & 1.12 & 1.26 & 1.36 & 1.41 & 1.46 \\
\hline
\end{tabular}

If $\mathrm{CR}<0.1$, then the consistency of judgment matrix is up to the standard. If not, readjust the judgment matrix.

4.3.2 Computation example of single hierarchical arrangement

(1) Computation result of single hierarchy of target layer---rule layer

$$
\lambda_{\max }=4.0435, w=\left(\begin{array}{c}
0.1998 \\
0.5222 \\
0.1998 \\
0.0781
\end{array}\right), C I=0.0145, C R=0.0163
$$

From the result we can know the function adaptability, execution efficiency, usability and compatibility and the consistency corresponding to judgment matrix are up to the standards. Execution efficiency quality characteristic is the most important comparing to other quality characteristics. 
(2) Computation result of function adaptability

$$
\lambda_{\max }=3.0536, w=\left(\begin{array}{c}
0.5278 \\
0.3325 \\
0.1396
\end{array}\right), C I_{1}=0.0268, C R_{1}=0.0462
$$

From the result, it is known that as to "functional adaptability" judging the satisfying requirements of consistency of judgment matrix, functional completeness is more important than other quality sub characteristics.

(3) Computation result of execution efficiency

$$
\lambda_{\max }=3.0536, w=\left(\begin{array}{c}
0.1571 \\
0.5936 \\
0.2493
\end{array}\right), C I_{2}=0.0268, C R_{2}=0.0462
$$

From the result, we can know that as to "execution efficiency" judging the satisfying requirements of consistency of judgment matrix, resource utilization account for the most proportion in the quality sub characteristic "execution efficiency".

(4) Computation result of usability

$$
\lambda_{\max }=3.0539, \quad w=\left(\begin{array}{c}
0.2519 \\
0.1593 \\
0.5889
\end{array}\right), C I_{3}=0.027, C R_{3}=0.0465
$$

From the result, we can know that as to "usability" judging the satisfying requirements of consistency of judgment matrix, accessibility is more important comparing to other quality sub characteristics.

(5) Computation result of compatibility

$$
\lambda_{\max }=2.0000, \quad w=\left(\begin{array}{l}
0.6667 \\
0.3333
\end{array}\right), C I_{4}=0, C R_{4}=0
$$

From the result, we can know that as to "compatibility" judging the satisfying requirements of consistency of judgment matrix, coexistence accounts for the most proportion in the quality sub characteristic "compatibility"

\subsection{Total Hierarchical Arrangement}

After finishing the single hierarchical arrangement, the relative importance of corresponding sub characteristics in each rule of rule layer is confirmed, that is to say, the corresponding emphasis in each characteristics evaluation is confirmed. But it is obviously not scientific and reasonable enough to evaluate only the single characteristics in the communication system software quality evaluation. It is also not up to the comprehensive standards of the actual war environment to the communication system. So we need to know the comprehensive weighted value of each bottom layer sub characteristics relative to communication system software quality, that is, the total hierarchical arrangement of project hierarchy needs to be done.

\subsubsection{Computation process of total hierarchical arrangement}

Total hierarchical arrangement is the comprehensive arrangement which is done to all the elements from the second layer to the bottom layer relative to the overall target in the target layer. The specific computation process is as follows:

(1) Calculate the comprehensive weight vector of elements of No. k layer

Suppose $W^{k}$ is the comprehensive weight vector of No. $\mathrm{k}$ layer in the total hierarchical arrangement, $w^{k}$ is the weight matrix built by the single hierarchical arrangement weight vector corresponding to each element in No. k layer relative to element in the above layer. The rest layers can be done in the same manner. The comprehensive weight vector of No. $\mathrm{k}$ layer element is calculated as follows:

$$
W^{k}=w^{k} * w^{k-1} * w^{k-2} * \ldots \ldots \ldots \ldots . . . . W^{2}
$$

(2) Do the general consistency check of No.K layer

After the total hierarchical arrangement, the general consistency check will be done to check if 
the inconsistency error accumulated in each layer is in the effective range. The specific computation process is as follows:

$$
C R^{k}=C R^{k-1}+\frac{\sum_{j=1}^{j=m} C I_{j}{ }^{k} * a_{j}}{\sum_{j=1}^{j=m} R I_{j}{ }^{k} * a_{j}}
$$

In it, $C R^{k}$ is the scale value of total consistency in No. K layer, $C R^{k-1}$ is the scale value of total consistency in No. K-1 layer, $C I_{j}{ }^{k}$ is the consistency index value gotten by using the No. $\mathrm{j}$ element in No. K-1 layer as the principle $R I_{j}{ }^{k}$ is the average random consistency index value gotten by using the No. $\mathrm{j}$ element in No. K-1 layer as the principle $a_{j}$ is the comprehensive weighted value of No. $\mathrm{j}$ element in No. K-1 layer.

\subsubsection{Computation Example of Total Hierarchical Arrangement}

It can be known from the computation process of total hierarchical arrangement that the total hierarchical arrangement of each element in the bottom layer needs the result of each layer's single hierarchical arrangement. And when the comprehensive consistency check is done, the general consistency test value and the comprehensive weighted value of each element should be brought to the general consistency check of the next layer. So the example of single hierarchical arrangement is used to explain it:

Single hierarchical arrangement weight matrix of each element in the project layer is got from the single hierarchical arrangement:

$$
W^{3}=\left[\begin{array}{cccc}
0.5278 & 0 & 0 & 0 \\
0.3325 & 0 & 0 & 0 \\
0.1396 & 0 & 0 & 0 \\
0 & 0.1571 & 0 & 0 \\
0 & 0.5936 & 0 & 0 \\
0 & 0.2493 & 0 & 0 \\
0 & 0 & 0.2519 & 0 \\
0 & 0 & 0.1593 & 0 \\
0 & 0 & 0.5889 & 0 \\
0 & 0 & 0 & 0.6667 \\
0 & 0 & 0 & 0.3333
\end{array}\right]
$$

weight vector of target layer-rule layer: $W^{2}=\left(\begin{array}{c}0.1998 \\ 0.5222 \\ 0.1998 \\ 0.0781\end{array}\right)$

So the comprehensive weight vector of each element in the project layer is:

$$
W^{3}=\left[\begin{array}{cccc}
0.5278 & 0 & 0 & 0 \\
0.3325 & 0 & 0 & 0 \\
0.1396 & 0 & 0 & 0 \\
0 & 0.1571 & 0 & 0 \\
0 & 0.5936 & 0 & 0 \\
0 & 0.2493 & 0 & 0 \\
0 & 0 & 0.2519 & 0 \\
0 & 0 & 0.1593 & 0 \\
0 & 0 & 0.5889 & 0 \\
0 & 0 & 0 & 0.6667 \\
0 & 0 & 0 & 0.3333
\end{array}\right] *\left(\begin{array}{l}
0.1998 \\
0.5222 \\
0.1998 \\
0.0781
\end{array}\right)=\left(\begin{array}{l}
0.1055 \\
0.0664 \\
0.0279 \\
0.0820 \\
0.3100 \\
0.1302 \\
0.0503 \\
0.0318 \\
0.1177 \\
0.0521 \\
0.0260
\end{array}\right)
$$

Because the total hierarchical arrangement of the third layer needs to be accumulated layer by layer, the general consistency check needs to be done to the third layer:

Because the consistency index value of single hierarchical arrangement of this layer relative to the above layer and the average random consistency index value are $C I_{1}=0.0268, C I_{2}=$ $0.0268, C I_{3}=0.027, C I_{4}=0 ; R I_{1}=0.58, R I_{2}=0.58, R I_{3}=0.58 R I_{4}=0 ;$ and the general consistency scale value of the above layer $C R^{2}=0.0163, C R^{3}=0.0462+0.0163=0.0625<0.1$. Therefore, the total arrangement weight vector of the third layer is up to the standard and can be used. The total arrangement weighted value of indexes in the bottom layer is shown in Figure 2. 


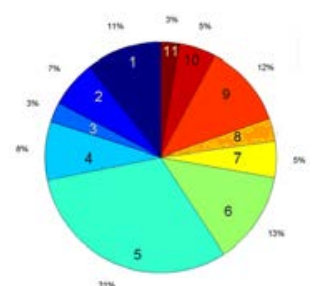

Figure 2 Result of total hierarchical arrangement of communication system In it, the meaning of each serial number is shown in the following figure

\begin{tabular}{|c|c|c|c|c|c|c|}
\hline No & 1 & 2 & 3 & 4 & 5 & 6 \\
\hline $\begin{array}{c}\text { Sub } \\
\text { characteristics }\end{array}$ & $\begin{array}{l}\text { Functional } \\
\text { completene }\end{array}$ & $\begin{array}{l}\text { Functional } \\
\text { correctness }\end{array}$ & $\begin{array}{l}\text { Functional } \\
\text { adaptabilit } \\
\mathrm{y}\end{array}$ & $\begin{array}{l}\text { Time } \\
\text { response }\end{array}$ & $\begin{array}{l}\text { Resource } \\
\text { usability }\end{array}$ & $\underset{\mathrm{y}}{\text { Capacit }}$ \\
\hline No & 7 & 8 & $y$ & 10 & 11 & \\
\hline $\begin{array}{l}\text { Sub } \\
\text { characteristics }\end{array}$ & $\begin{array}{l}\text { Learn } \\
\text { ability }\end{array}$ & Operability & $\begin{array}{c}\text { Accessibili } \\
\text { ty }\end{array}$ & $\begin{array}{c}\text { Compossibilit } \\
\mathrm{y}\end{array}$ & $\underset{y}{\text { Practicalit }}$ & \\
\hline
\end{tabular}

From Figure 2, we can know the comprehensive weighted value of sub characteristics in 11 bottom layers. Among them, the weighted value of resource usability accounts for $31 \%$ and it is the most important. So according to the judgment matrix confirmed in the hierarchical structure, it is finally confirmed that the quantized value of resource usability should be confirmed correctly before finally confirming the comprehensive index of communication system software quality. Then according to the number of weighted value, confirm the value of sub characteristics accordingly. Then the quantization evaluation of the communication system software quality is done in the way of linear weighting sum.

\subsection{Extreme Judgment}

Many experts can confirm the weight of quality characteristics and sub characteristics according to the above computation process and confirm whether there is abnormal value in the weighed value through the formula $(1) \sim(3)$. The results are shown in the following chart.

\begin{tabular}{|c|c|c|c|c|c|c|c|c|c|c|c|}
\hline $\begin{array}{c}\text { No. of } \\
\text { the } \\
\text { weight }\end{array}$ & $\omega_{1}$ & $\omega_{2}$ & $\omega_{3}$ & $\omega_{4}$ & $\omega_{5}$ & $\omega_{6}$ & $\omega_{7}$ & $\omega_{8}$ & $\omega_{9}$ & $\omega_{10}$ & $\omega_{11}$ \\
\hline $\bar{\eta}_{i}$ & 0.1157 & 0.0704 & 0.0205 & 0.0798 & 0.298 & 0.13 & 0.0468 & 0.0289 & 0.12 & 0.0498 & 0.02 \\
\hline $\mathrm{S}$ & 0.065 & 0.015 & 0.003 & 0.012 & 0.0085 & 0.001 & 0.007 & 0.0085 & 0.001 & 0.001 & 0.0025 \\
\hline $\begin{array}{c}\text { Judgm } \\
\text { ent } \\
\text { result }\end{array}$ & $\begin{array}{c}\text { Qualifi } \\
\text { ed }\end{array}$ & $\begin{array}{c}\text { Qualifi } \\
\text { ed }\end{array}$ & $\begin{array}{c}\text { Qualifi } \\
\text { ed }\end{array}$ & $\begin{array}{c}\text { Qualifi } \\
\text { ed }\end{array}$ & $\begin{array}{c}\text { Qualifi } \\
\text { ed }\end{array}$ & $\begin{array}{c}\text { Qualifi } \\
\text { ed }\end{array}$ & $\begin{array}{c}\text { Qualifi } \\
\text { ed }\end{array}$ & $\begin{array}{c}\text { Qualifi } \\
\text { ed }\end{array}$ & $\begin{array}{c}\text { Qualifi } \\
\text { ed }\end{array}$ & $\begin{array}{c}\text { Qualifi } \\
\text { ed }\end{array}$ & $\begin{array}{c}\text { Qualifi } \\
\text { ed }\end{array}$ \\
\hline
\end{tabular}

\section{Conclusion}

In this paper, the weighted value of software quality model is confirmed through analytic hierarchy process and extreme judgment rejection method. The method scientifically and reasonably makes the qualitative problem become quantitative and solves the present problems in the research on weighted value confirming of software quality model like the method is relatively rough and how to reject the abnormal value during the weight judgment. It also lays the solid foundation for the further research and confirmation of the software quality model which is up to the real standards and is easy to operate.

\section{References}

[1] Lu Ziyi, Fan Jianhua. Tactics Communication System Efficiency Evaluation Based on Analytic Hierarchical Process [J].Modern Electronic Technology,2011,34 (1) :57-60.

[2] Li Yuan, Yang Jianjun. Combat Drill Performance Evaluation of Antiaircraft Missile Weapon System Based on AHP [J]. Tactical Missile Control Technology,2008,30 (2) :50-52.

[3] Duan Shoufu, Yang Kai, Wang Jun, Xu Hui. Operational Effectiveness Evaluation of Aviation 
Wireless Communication System [J]. Firepower, Command and Control,2010,35 (11) : 117-119. [4] Yan Chongchong, Hao Yongsheng. Aerial Target Threat Degree Estimation Based on Analytic Hierarchical Process [J]. Computer Technology and Automation,2011,30 (2) :118-121.

[5] Zhou Chongbo, Lou Jungang, Cheng Long. Test Case Reduction Algorithm Based on Matrix Rank Transformation [J].Computer Application Research.2013,30(03):779-782. 